\title{
EFFECTS OF REPEATED LAUNDERING ON THERMAL COMFORT PROPERTIES OF CELLULOSIC KNITTED FABRICS
}

\author{
OĞUZ DEMIRYÜREK, İNCI GÜLEYÜPOĞLU** and EDA TURHAN* \\ *Erciyes University, Textile Engineering Department, 38039, Kayseri, Turkey \\ ** Ministry of Defence, Quality Management Department of Ankara, Turkey \\ $\bowtie$ Corresponding author: Oğuz Demiryürek, oguzdemiryurek@gmail.com
}

Received February 9, 2019

\begin{abstract}
Air and water vapour permeability, thickness and thermal resistance of fabrics are some of the most important parameters to determine clothing comfort. However, these parameters tend to change after laundering in daily use. In this study, changes in the thermal comfort properties of cellulosic fabrics used in underwear and sock production, due to repeated laundering, were investigated. For this purpose, $100 \%$ cotton, viscose, Viloft, Modal, Promodal and Tencel fabrics, in single jersey construction, were selected and the thickness, air permeability, water vapour permeability and thermal resistance of the fabrics were measured initially and after 5, 10 and 15 repeated launderings. The obtained data were analysed by statistical techniques. According to the results, increasing the number of laundering cycles decreases air permeability and increases thickness and thermal resistance, in general. However, relative water vapour permeability decreases up to a number of laundering cycles and increases from this point on, upon further increasing the number of laundering cycles. The material type was found to be more influential than thickness on the thermal resistance values in this study. In conclusion, repeated laundering and material type significantly affect the comfort properties of fabrics.
\end{abstract}

Keywords: cellulosic fibres, thickness, air permeability, water vapour permeability, thermal comfort, repeated laundering

\section{INTRODUCTION}

Clothing comfort has become one of the most important properties of fabrics. Although the word "comfort" can be related to physiological and psychological or sensorial factors, in addition to these parameters, thermal comfort properties are also important for determining the comfort of fabrics in an objective way. ${ }^{1,2}$ Thermal comfort can be measured by air and water permeability, drying ability and thermal resistance of fabrics. However, these parameters may change upon wearing and washing a fabric several times during use. The comfort properties of raw fabrics, produced from pure cotton or regenerated cellulosic fibres or the blends of these materials, in knitted or woven structures, have been investigated by several researchers. ${ }^{2-8}$ The linear density of yarn, fabric thickness, fibre content and knit structures have been found to be important parameters, affecting comfort properties. In order to simulate real use conditions, some of the properties of the fabrics have been evaluated after repeated launderings by several researchers.
Dimensional, ${ }^{9-10}$ wrinkle, ${ }^{11-12}$ breaking strength and breaking elongation of denim fabrics, ${ }^{14}$ bleaching and napping durability and thermal comfort properties ${ }^{1}$ were investigated after applying repeated launderings. Wicking and drying properties of seamless garments, ${ }^{15}$ air and water permeability and moisture management properties of denim fabrics ${ }^{16}$ were also investigated. The related parameters were significantly affected by repeated laundering. The thermal insulation and morphology of natural and synthetic filled outdoor sportswear, upon repeated laundering without using detergent and dry cleaning, has been researched and it was concluded that thermal insulation increases in synthetic fibres upon repeated laundering, in general. ${ }^{18}$ Nayak et al. investigated the thermophysiological comfort properties of aramid fabrics upon repeated laundering and they found that the fabric thickness, areal density, thermal resistance and water vapour resistance values increased with the number of laundering cycles, whereas the air 
permeability decreased because of fabric shrinkage and swelling. ${ }^{19}$ The effect of laundering on the thermal and water transfer properties of laminated nanofiber web for wear was also investigated. $^{20}$

Cotton and regenerated cellulosic fibres are generally preferred for next-to-skin fabrics, such as underwear and socks, for their high moisture regain and natural feeling during wear. It was seen that fabric thermal properties changed with repeated launderings, by taking into consideration previous studies. The studies on the thermal comfort of textile fabrics reported in the literature are scarce. Although a comprehensive literature survey has been carried out, we have not encountered a specific study investigating the changes in thermal comfort properties of novel and/or conventional cellulosic fabrics after repeated launderings, which simulate regular use conditions. In order to close the gap in the literature, the thermal comfort properties of cotton and commonly used regenerated cellulosic fabrics, such as viscose, Viloft, Modal, Promodal and Tencel, after repeated launderings using detergent have been investigated in this research.

\section{EXPERIMENTAL}

In this study, $100 \%$ cotton, viscose, Viloft, Modal, Promodal and Tencel fabrics, in single jersey knitted fabric constructions, were provided by Karsu Tekstil Company, Turkey, as sample materials. The yarn linear density of those fabrics was fixed at 20 tex and the twist factor of the yarns were determined as $\alpha_{\mathrm{e}}=$ 3.7. The initial properties of the single jersey knitted fabrics are listed in Table 1. Viloft is a novel fibre and called modified viscose or "thermal viscose" by the producer. The chemical composition of this fiber is identical with that of viscose, however, the crosssection and surface characteristics are different. Viloft has a crenulated surface and rectangular cross-section, whereas viscose has a curly, but round cross-section. Modal, Promodal and Tencel are polynosic fibers, having an elliptical cross-section, which are known for their high tenacity properties, compared to viscose.
Promodal is the blend of Modal and Tencel fibers. Tencel is also known for its fibrillation property with mechanical effects due to weak cross-bonds between macrofibrils in the fibre structure. ${ }^{5}$

The thickness of fabrics was measured by an "Elastocon" thickness measurement device according to TS 7128 EN ISO 5084 standard. Porosity values of the fabrics were calculated as:

$P=[1-(m / \rho h)] 100$

where $P$ is the porosity (\%), $m$ is the fabric weight $\left(\mathrm{g} / \mathrm{m}^{2}\right), \rho$ is the fibre density $\left(\mathrm{g} / \mathrm{cm}^{3}\right)$, and $h$ is the fabric thickness in mm. Fabric density $(d)$ was also calculated directly from the below equation as:

$d\left(\mathrm{~g} / \mathrm{cm}^{3}\right)=m /(1000 h)$

Air permeability was measured by an SDL Atlas device according to TS 391 EN ISO 9237. Air permeability tests were performed by applying $100 \mathrm{~Pa}$ pressure through $20 \mathrm{~cm}^{2}$ fabrics. Water vapour permeability tests were carried out by using Permetest, which works on the principle of heat flux sensing, according to ISO 11092 test standard. A sweating guarded hotplate was used for measuring the thermal resistance $\left(R_{c t}\right)$ of fabrics by an MTW testing device according to ISO 11092 standard under steady-state conditions. In this test, the porous plate, which simulates the human skin, was fixed at $35{ }^{\circ} \mathrm{C}$. The relative humidity inside the testing device was $65 \%$, the temperature of circulating air was determined at 20 ${ }^{\circ} \mathrm{C}$ and air flow at $1 \mathrm{~m} / \mathrm{s}$. The initial thermal resistance $\mathrm{R}_{\mathrm{ct} 0}$ under steady-state conditions without the sample was recorded as $\mathrm{R}_{\mathrm{ct} 0}=0.0569{ }^{\circ} \mathrm{C} \mathrm{m} / \mathrm{W}$. The samples were prepared to $300 \times 300 \mathrm{~mm}$ dimensions and conditioned. The next-to-skin side of the fabrics was placed onto the plate and the thermal resistance of the fabrics was measured. The initial thermal resistance of the fabrics should be subtracted from the measured value. Thus, the thermal resistance of a sample was calculated as follows:

$R_{c t}=\left[A\left(T_{s}-T_{a}\right) / H\right]-R_{c t 0}$

where $T_{s}$ and $T_{a}$ are the temperatures of the plate and circulating air $\left({ }^{\circ} \mathrm{C}\right)$, respectively; $A$ is the sample area in $\mathrm{m}^{2}$ and $H$ is the electrical power $(W)$ supplied in order to keep the plate at $35^{\circ} \mathrm{C}$.

Table 1

Unlaundered fabric properties

\begin{tabular}{lccccc}
\hline Fabric & $\begin{array}{c}\text { Courses-Wales, } \\
\mathrm{cm}\end{array}$ & $\begin{array}{c}\text { Weight } \\
\left(\mathrm{g} / \mathrm{m}^{2}\right)\end{array}$ & $\begin{array}{c}\text { Thickness } \\
(\mathrm{mm})\end{array}$ & $\begin{array}{c}\text { Porosity } \\
(\%)\end{array}$ & $\begin{array}{c}\text { Fabric density } \\
\left(\mathrm{g} / \mathrm{cm}^{3}\right)\end{array}$ \\
\hline Cotton & $19-23$ & 123.4 & 0.627 & 87.1 & 0.197 \\
Viscose & $20-14$ & 159.3 & 0.579 & 81.9 & 0.275 \\
Viloft & $20-14$ & 146.7 & 0.658 & 85.3 & 0.223 \\
Modal & $18-13$ & 131.0 & 0.578 & 85.1 & 0.227 \\
Promodal & $19-14$ & 141.7 & 0.591 & 84.2 & 0.240 \\
Tencel & $22-13$ & 149.3 & 0.616 & 84.1 & 0.242 \\
\hline
\end{tabular}


Laundering was carried out using an Atlas FOM71CLS washing machine according to TS EN ISO 6330 standard, at $40{ }^{\circ} \mathrm{C}$ and using "Reference detergent 3" mentioned in the standard. The samples were laundered 5, 10 and 15 times and dried under standard atmosphere conditions $\left(20 \pm 2{ }^{\circ} \mathrm{C}\right.$ and $65 \% \pm$ $2 \mathrm{RH})$. Unlaundered and laundered samples were tested. All the tests were performed 3 times as replications and the data were introduced into statistical analysing software (Design Expert 6.0.6). The general factorial design was conducted by determining the material type and repeated laundering factors as independent variables, while thickness, air permeability, water permeability and thermal resistance as dependent or response variables. The best model was selected by means of basic statistical tests, such as $\mathrm{R}^{2}$, standard deviation, Predicted Errors Sum of Squares (PRESS) and lack of fit tests for each response. According to these tests, the cubic model was suggested by the software for each response variable. The Analysis of Variance (ANOVA) was constructed in order to reveal the significance of the model parameters for all response variables. In the analysis, "A" represented the material type as a categorical factor and "B" represented the number of repeated launderings as a numerical factor. The significance of these factors on the response was evaluated simply by taking the p-values into consideration. The effect of the related parameter on the response is significant if the p-value is lower than 0.05 . The contribution or the effect of the model terms to the model was also displayed in the ANOVA tables. It can be calculated by dividing the sum of squares value of a related model parameter to the Corrected Total (Cor. Total) Sum of Squares. The regression curves were also displayed for each response variable.

\section{RESULTS AND DISCUSSION}

The thermal comfort properties of textile fabrics are mainly dependent on their thickness, porosity, air permeability, relative water permeability and thermal resistance values. In addition, these parameters are commonly interrelated to each other. Therefore, the mean of the thickness values measured and the porosity and fabric density values calculated were introduced into Table 2 for unlaundered and laundered materials. As may be noted in this table, thickness increases, porosity slightly increases and density decreases by increasing the number of laundering cycles, in general. The statistical investigation on thickness, porosity and density was carried out and given as a summary at the bottom of the table. According to the results, "material type" and "repeated laundering" factors significantly affected the thickness, porosity and fabric density in a $95 \%$ confidence interval. The
R-squared values, which indicate the explanation ratio of the related response to the input factors, were obtained as $0.953,0.973$ and 0.970 for thickness, porosity and fabric density factors, respectively. In other words, $95.3 \%$ of thickness is explained, while the rest of $4.7 \%$ may be related to interference or other factors that are not considered in present study or may be simply an error.

The statistical analyses are presented for thickness, air permeability, water vapour permeability and thermal resistance, respectively.

\section{Thickness}

The change in fabric thickness directly affects the thermal comfort properties. The $\mathrm{R}^{2}$ value of the model developed is obtained as 0.9668 for thickness in the ANOVA table (Table 3). In other words, the model developed explained $96.68 \%$ of thickness. According to the results, the material type and the number of repeated launderings are significant factors. Considering the contributions of the model terms, the contribution of the material type (A) is $43.04 \%$, whereas the total effect or contribution of repeated laundering $\left(\mathrm{B}+\mathrm{B}^{2}+\mathrm{B}^{3}\right)$ is $46.14 \%$. It can be inferred that both material type and repeated laundering affected thickness. Here, the quadratic and cubic effects of material type (A) could not be calculated, since it is a categorical factor.

In order to see the thickness variation with the number of repeated launderings according to the material types, the regression curves are presented in Figure 1. Thickness increased rapidly up to 5 laundering cycles for all material types, which could be related to the fibres protruding from the fabrics owing to the mechanical effect of laundering and detergent. However, it tended to be nearly constant for cotton and Tencel from 5 up to 12-13 laundering cycles. Thereafter, a small increase could also be seen for these fabrics up to 15 launderings. The fibrillation of Tencel fibres emerged because of the mechanical effect of laundering and detergent, providing a higher specific surface area, which results in more interfriction of fibres or fibrils. It may result in protruding fibres from the fabrics, which caused thickness to increase. Similarly, cotton already has a high specific surface area and the number of laundering cycles increased the thickness of fabrics smoothly.

The trend of the thickness variation curves for Viloft and viscose are similar, but the one for Viloft is higher than that for viscose. It can be 
OĞUZ DEMİRYÜREK et al.

related to the cross-section of the fibres, as Viloft has a higher specific surface area than viscose, which caused more fibre inter-friction in the fabrics. The thickness of Modal increases up to 5 laundering cycles, however it decreases from this point to 15 laundering cycles, dissimilarly to other fibres. The high wet strength of Modal may tend to hold each fibre in the fabric and the fabric gets a more compact structure. Since Promodal is the blend of Tencel and Modal, the thickness variation obtained for Promodal lies between those for two previous fibres.

Table 2

Evolution of thickness, porosity and fabric density as a function of laundering or different material types

\begin{tabular}{|c|c|c|c|c|}
\hline Material type & Laundering cycle & Thickness (mm) & Porosity (\%) & Fabric density $\left(\mathrm{g} / \mathrm{cm}^{3}\right)$ \\
\hline \multirow{4}{*}{ Cotton } & Unlaundered & 0.627 & 87.1 & 0.197 \\
\hline & 5 times laundered & 0.744 & 89.0 & 0.167 \\
\hline & 10 times laundered & 0.744 & 88.9 & 0.169 \\
\hline & 15 times laundered & 0.777 & 89.3 & 0.163 \\
\hline \multirow{4}{*}{ Viscose } & Unlaundered & 0.579 & 81.9 & 0.275 \\
\hline & 5 times laundered & 0.678 & 84.4 & 0.237 \\
\hline & 10 times laundered & 0.690 & 84.5 & 0.236 \\
\hline & 15 times laundered & 0.703 & 84.7 & 0.233 \\
\hline \multirow{4}{*}{ Viloft } & Unlaundered & 0.658 & 85.3 & 0.223 \\
\hline & 5 times laundered & 0.725 & 86.5 & 0.205 \\
\hline & 10 times laundered & 0.723 & 86.3 & 0.209 \\
\hline & 15 times laundered & 0.722 & 85.9 & 0.214 \\
\hline \multirow{4}{*}{ Modal } & Unlaundered & 0.578 & 85.1 & 0.227 \\
\hline & 5 times laundered & 0.639 & 86.2 & 0.210 \\
\hline & 10 times laundered & 0.619 & 85.3 & 0.224 \\
\hline & 15 times laundered & 0.600 & 84.5 & 0.235 \\
\hline \multirow{4}{*}{ Promodal } & Unlaundered & 0.591 & 84.2 & 0.240 \\
\hline & 5 times laundered & 0.684 & 86.1 & 0.211 \\
\hline & 10 times laundered & 0.669 & 85.4 & 0.222 \\
\hline & 15 times laundered & 0.682 & 85.3 & 0.223 \\
\hline \multirow{4}{*}{ Tencel } & Unlaundered & 0.616 & 84.1 & 0.242 \\
\hline & 5 times laundered & 0.694 & 85.5 & 0.221 \\
\hline & 10 times laundered & 0.706 & 85.4 & 0.223 \\
\hline & 15 times laundered & 0.726 & 85.4 & 0.222 \\
\hline \multicolumn{2}{|l|}{$\mathrm{CV}(\%)$} & 2.62 & 0.46 & 2.88 \\
\hline \multicolumn{2}{|l|}{$\mathrm{R}^{2}$} & 0.953 & 0.973 & 0.970 \\
\hline \multicolumn{2}{|l|}{ p-value } & $<0.00001$ & $<0.00001$ & $<0.00001$ \\
\hline \multicolumn{2}{|c|}{ Significance (\%95 CI) } & Significant & Significant & Significant \\
\hline
\end{tabular}

Table 3

ANOVA for thickness

\begin{tabular}{|c|c|c|c|c|c|c|c|}
\hline Source & $\begin{array}{l}\text { Sum of } \\
\text { squares }\end{array}$ & $\begin{array}{c}\text { Contribution } \\
(\%)\end{array}$ & $\mathrm{DF}$ & $\begin{array}{l}\text { Mean } \\
\text { square }\end{array}$ & F-value & p-value & Significance \\
\hline Model & 0.22 & 96.68 & 18 & 0.012 & 84.99 & $<0.0001$ & significant \\
\hline A & 0.099 & 43.04 & 5 & 0.020 & 137.19 & $<0.0001$ & significant \\
\hline B & 0.070 & 30.43 & 1 & 0.070 & 486.34 & $<0.0001$ & significant \\
\hline $\mathrm{B}^{2}$ & 0.027 & 11.74 & 1 & 0.027 & 183.86 & $<0.0001$ & significant \\
\hline $\mathrm{AB}$ & 0.016 & 6.96 & 5 & $3.10 .4 * 10^{-3}$ & 21.51 & $<0.0001$ & significant \\
\hline $\mathrm{B}^{3}$ & $9.120 * 10^{-3}$ & 3.97 & 1 & $9.120 * 10^{-3}$ & 63.21 & $<0.0001$ & significant \\
\hline $\mathrm{AB}^{2}$ & $4.078 * 10^{-4}$ & 0.18 & 5 & $8.156 * 10^{-5}$ & 0.57 & 0.7261 & not significant \\
\hline Residual & $7.647 * 10^{-3}$ & 3.32 & 53 & $1.443 * 10^{-4}$ & & & \\
\hline Lack of fit & $8.087 * 10^{-4}$ & 0.35 & 5 & $1.617 * 10^{-4}$ & 1.14 & 0.3547 & not significant \\
\hline Pure error & $6.838 * 10^{-3}$ & 2.97 & 48 & $1.425^{*} 10^{-4}$ & & & \\
\hline Cor. total & 0.23 & 100.00 & 71 & & & & \\
\hline
\end{tabular}




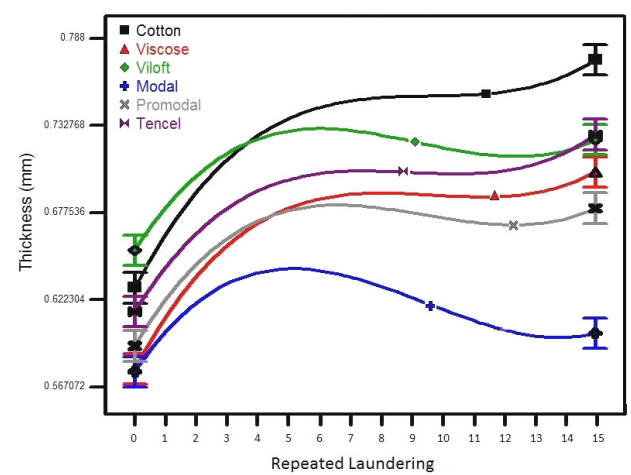

Figure 1: Regression curves for thickness

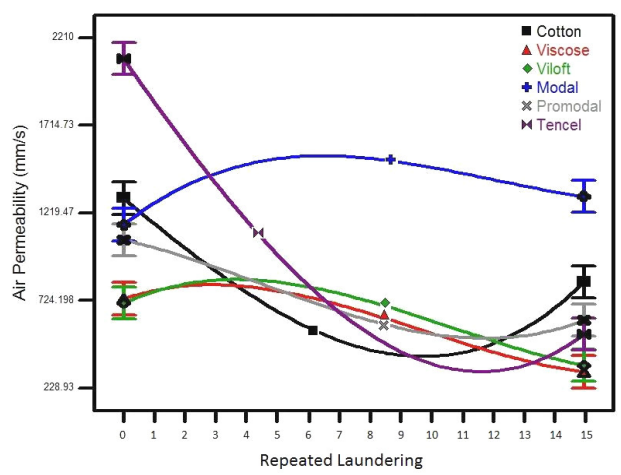

Figure 2: Regression curves for air permeability

Table 4

ANOVA for air permeability

\begin{tabular}{|c|c|c|c|c|c|c|c|}
\hline Source & $\begin{array}{l}\text { Sum of } \\
\text { squares }\end{array}$ & $\begin{array}{c}\text { Contribution } \\
(\%)\end{array}$ & $\mathrm{DF}$ & $\begin{array}{l}\text { Mean } \\
\text { square }\end{array}$ & F-value & p-value & Significance \\
\hline Model & $1.320 * 10^{7}$ & 95.09 & 18 & $7.332 * 10^{5}$ & 57.00 & $<0.0001$ & significant \\
\hline A & $4.985 * 10^{6}$ & 35.91 & 5 & $9.970 * 10^{5}$ & 77.51 & $<0.0001$ & significant \\
\hline $\mathrm{B}$ & $2.971 * 10^{6}$ & 21.40 & 1 & $2.971 * 10^{6}$ & 230.94 & $<0.0001$ & significant \\
\hline $\mathrm{B}^{2}$ & $2.815^{*} 10^{5}$ & 2.03 & 1 & $2.815^{*} 10^{5}$ & 21.88 & $<0.0001$ & significant \\
\hline $\mathrm{AB}$ & $2.641 * 10^{6}$ & 19.03 & 5 & $5.282 * 10^{5}$ & 41.07 & $<0.0001$ & significant \\
\hline $\mathrm{B}^{3}$ & 80580.54 & 0.001 & 1 & 80580.54 & 6.26 & 0.0154 & significant \\
\hline $\mathrm{AB}^{2}$ & $2.239 \mathrm{E} * 10^{6}$ & 16.13 & 5 & $4.477 * 10^{5}$ & 34.81 & $<0.0001$ & significant \\
\hline Residual & $6.817 * 10^{5}$ & 4.91 & 53 & 12863.08 & & & \\
\hline Lack of fit & $4.952 * 10^{5}$ & 3.57 & 5 & 99041.71 & 25.49 & $<0.0001$ & significant \\
\hline Pure error & $1.865 * 10^{5}$ & 1.34 & 48 & 3886.14 & & & \\
\hline Cor. total & $1.388 * 10^{7}$ & 100.00 & 71 & & & & \\
\hline
\end{tabular}

\section{Air permeability}

Air permeability is one of the most important factors affecting the comfort properties of fabrics. The ANOVA for air permeability is demonstrated in Table 4. The $\mathrm{R}^{2}$ value of the model developed is 0.9509 . In other words, the model developed explained $95.09 \%$ of air permeability. According to the results, the material type and the number of repeated launderings are significant factors. Considering the contributions of the model terms, the contribution of the material type (A) is $35.91 \%$, whereas the total effect or contribution of repeated laundering $\left(\mathrm{B}+\mathrm{B}^{2}+\mathrm{B}^{3}\right)$ is $23.43 \%$. The interaction of the material type and laundering cycles is also significant and has a contribution of $35.16 \%\left(\mathrm{AB}+\mathrm{AB}^{2}\right)$ to air permeability.

Air permeability can be identified as "air flow passing through a fabric under a given air pressure". It can be related to the thickness, porosity, fabric density, fibre surface characteristics and yarn properties, which may increase or decrease the air flow resistance. Commonly, these parameters are interrelated to each other. The air permeability variation with repeated launderings, according to material types, is shown as regression curves in Figure 2. At initial measurements, the air permeability of Tencel is the highest; those of Modal, cotton and Promodal are moderate and similar to each other; while those of Viloft and viscose are the lowest. Although Tencel has low porosity, moderate thickness and relatively high fabric density, maximum air permeability is achieved for this fibre. It may be related to the cross-section characteristics of Tencel fibre, which has a smooth and round cross-section, allowing minimum air flow resistance. However, due to the fibrillation characteristics of Tencel fibres, resulting in a higher specific surface area by the mechanical effect of laundering, air permeability decreases rapidly, which can be related to increased air resistance of this fabric. Similar trends may be seen for cotton and Promodal fabrics, in which air permeability decreased rapidly up to 10-13 laundering cycles and slowly increased from this point up to the $15^{\text {th }}$ laundering cycle. The increase in air permeability after 10-13 launderings may be related to the fibre or weight 
loss by mechanical effect of laundering, which is related to low fabric density upon repeated laundering (Table 2).

The trends of the curves are similar for Modal, viscose and Viloft, i.e. air permeability increases up to 5-7 launderings and decreases slowly to 15 launderings. Midha et al. showed that the air permeability of cotton weft denim fabrics increases up to 10 laundering cycles, however, it decreases gradually from 10 cycles to 30 laundering cycles. $^{16}$ The air permeability variations for these fabrics can be related with their thickness variations, as shown in Figure 1, and porosity, as demonstrated in Tables 1 and 2. The porosity of these fabrics firstly increased and then decreased with laundering. A decrease in thickness increases the volume of air passing through the fabrics. At the end of the laundering cycles ( 15 cycles), the maximum air permeability due to the decrease in thickness is obtained for Modal fabrics. It may be related to the high wetstrength of Modal, which holds the fibres in the fabrics, resulting in less fibre loss and more compact structure of Modal fabrics upon repeated launderings. Since Promodal is the blend of Tencel and Modal, the obtained air permeability variation of Promodal lies between those of the other two fabrics. The behaviour of Viloft and viscose fabrics are similar to each other. However, the air permeability of Viloft is higher than that of viscose, which can be related to the thickness variation of these fibres, as shown in Figure 1, in which the thickness variation of Viloft is higher than that of viscose upon repeated laundering.

\section{Relative water vapour permeability}

The ANOVA for water vapour permeability is demonstrated in Table 5. The model developed is significant and the $\mathrm{R}^{2}$ value of the model is obtained as 0.7449 . According to the results, the material type and the linear, quadratic, cubic effects of the number of laundering cycles are significant factors. Considering the contributions of the model terms, the contribution of the material type (A) is $19.66 \%$, whereas the total contribution of repeated laundering $\left(\mathrm{B}+\mathrm{B}^{2}+\mathrm{B}^{3}\right)$ is $45.01 \%$. It can be inferred that repeated laundering is more influential than material type on water vapour permeability.

The relative water vapour permeability (RWVP) variation with repeated laundering according to the material types is shown in Figure 3. The RWVP of Tencel, cotton, viscose and
Viloft fabrics decreased up to 10 launderings and increased from this point to 15 launderings. A similar trend was reported in the study of Sumin et $a l .{ }^{20}$ where repeated laundering resulted in variations in the RWVP of laminated nanofiber webs. The decreasing trend in these fabrics may be related to the mechanical effect of laundering using detergent, which causes fibres to protrude from the fabric structure, resulting in an increase in thickness. However, increasing the laundering cycles (from 10 to 15 ) increased the mechanical effect on the fabrics, which may cause fibre loss in the fabric structure, thus leading to an increased RWVP.

The RWVP of Modal and Promodal fabrics firstly increased up to 5 launderings, then decreased to 10 launderings and increased again up to 15 launderings. In general, the RWVP of polynosic fibers, such as Modal and Promodal, is higher than for the rest of the fabrics. Tencel is different from these polynosic fibers since its fibrillation property, which yields a higher specific surface area, results in more resistance to water vapour, compared to Modal and Promodal. The minimum RWVP is obtained for Viloft, which can be related to its crenulated surface, which yields a higher specific surface area than in other fabrics. The RWVP in viscose fabrics is higher than in Viloft and lower than in cotton, as expected.

\section{Thermal resistance}

The ANOVA for thermal resistance is demonstrated in Table 6. The model developed is significant for thermal resistance and the $\mathrm{R}^{2}$ value of the model is 0.952 . According to the results, the material type and the number of launderings are significant factors. Considering the contributions of the model terms, the contribution of the material type (A) is $69.07 \%$, whereas the total contribution of repeated laundering $\left(B+B^{2}+B^{3}\right)$ is $16.97 \%$. It can be inferred that material type is more influential than repeated laundering on thermal resistance.

Figure 4 presents the thermal resistance variation of cellulosic fabrics with repeated laundering. Initially, the thermal resistance of Viloft fabric is the highest among the fabrics; cotton, Promodal and Modal fabrics are nearly equal; Tencel fabric is the lowest and viscose is slightly higher than Tencel. The maximum increase in thermal resistance is observed for cotton fabrics upon increasing the number of laundering cycles. There is no significant variation for Viloft fabrics as a 
function of repeated laundering. The thermal resistance of Promodal increased slightly up to 8 launderings, but decreased to its initial thermal resistance value by increasing the number of laundering cycles up to 15 . The thermal resistance of Modal fabric increased linearly upon increasing the number of laundering cycles.

Table 5

ANOVA for water vapour permeability

\begin{tabular}{lccccccc}
\hline Source & $\begin{array}{c}\text { Sum of } \\
\text { squares }\end{array}$ & $\begin{array}{c}\text { Contribution } \\
(\%)\end{array}$ & DF & $\begin{array}{c}\text { Mean } \\
\text { square }\end{array}$ & F-value & p-value & Significance \\
\hline Model & 803.92 & 74.49 & 18 & 44.66 & 8.60 & $<0.0001$ & significant \\
$\mathrm{A}$ & 212.14 & 19.66 & 5 & 42.43 & 8.17 & $<0.0001$ & significant \\
$\mathrm{B}$ & 5.71 & 0.53 & 1 & 5.71 & 1.10 & 0.2993 & not significant \\
$\mathrm{B}^{2}$ & 317.73 & 29.44 & 1 & 317.73 & 61.16 & $<0.0001$ & significant \\
$\mathrm{AB}$ & 47.94 & 4.44 & 5 & 9.59 & 1.85 & 0.1198 & not significant \\
$\mathrm{B}^{3}$ & 162.29 & 15.04 & 1 & 162.29 & 31.24 & $<0.0001$ & significant \\
$\mathrm{AB}^{2}$ & 58.11 & 5.38 & 5 & 11.62 & 2.24 & 0.0640 & not significant \\
Residual & 275.36 & 25.51 & 53 & 5.20 & & & \\
Lack of fit & 189.61 & 17.57 & 5 & 37.92 & 21.23 & $<0.0001$ & significant \\
Pure error & 85.75 & 7.95 & 48 & 1.79 & & & \\
Cor. total & 1079.27 & 100.00 & 71 & & & & \\
\hline
\end{tabular}

Table 6

ANOVA for thermal resistance

\begin{tabular}{lccccccc}
\hline Source & $\begin{array}{c}\text { Sum of } \\
\text { squares }\end{array}$ & $\begin{array}{c}\text { Contribution } \\
(\%)\end{array}$ & DF & $\begin{array}{c}\text { Mean } \\
\text { square }\end{array}$ & F-value & p-value & Significance \\
\hline Model & $2.494 * 10^{-3}$ & 95.20 & 18 & $1.385^{*} 10^{-4}$ & 58.45 & $<0.0001$ & significant \\
$\mathrm{A}$ & $1.809 * 10^{-3}$ & 69.07 & 5 & $3.618^{*} 10^{-4}$ & 152.65 & $<0.0001$ & significant \\
$\mathrm{B}$ & $2.612 * 10^{-4}$ & 9.97 & 1 & $2.612^{*} 10^{-4}$ & 110.18 & $<0.0001$ & significant \\
$\mathrm{B}^{2}$ & $1.825^{*} 10^{-4}$ & 6.97 & 1 & $1.825^{*} 10^{-4}$ & 76.98 & $<0.0001$ & significant \\
$\mathrm{AB}$ & $1.918^{*} 10^{-4}$ & 7.32 & 5 & $3.835^{*} 10^{-5}$ & 16.18 & $<0.0001$ & significant \\
$\mathrm{B}^{3}$ & $8.161 * 10^{-7}$ & 0.03 & 1 & $8.161^{*} 10^{-7}$ & 0.34 & 0.5599 & not significant \\
$\mathrm{AB}^{2}$ & $4.855^{*} 10^{-5}$ & 1.85 & 5 & $9.710^{*} 10^{-6}$ & 4.10 & 0.0032 & significant \\
Residual & $1.256^{*} 10^{-4}$ & 4.80 & 53 & $2.370^{*} 10^{-6}$ & & & \\
Lack of fit & $7.677 * 10^{-5}$ & 2.93 & 5 & $1.535^{*} 10^{-5}$ & 15.09 & $<0.0001$ & significant \\
Pure error & $4.885^{*} 10^{-5}$ & 1.87 & 48 & $1.018^{*} 10^{-6}$ & & & \\
Cor. total & $2.619 * 10^{-3}$ & 100.00 & 71 & & & & \\
\hline
\end{tabular}

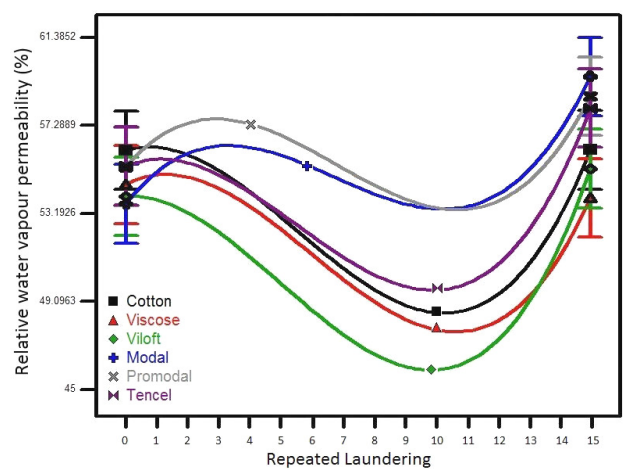

Figure 3: Regression curves for relative water vapour permeability (\%)

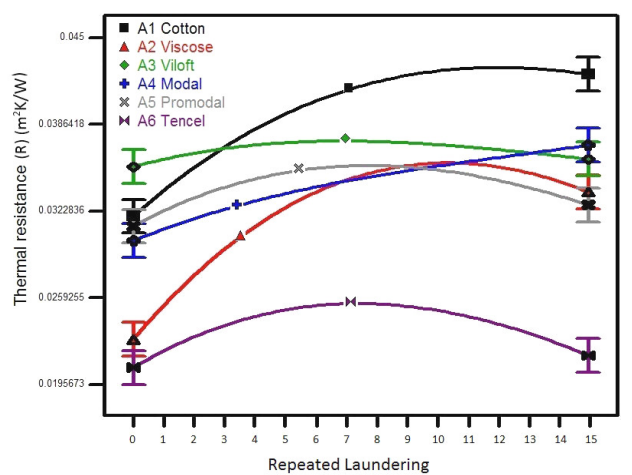

Figure 4: Regression curves for thermal resistance 
Viscose showed a rapid increase in thermal resistance up to 12 launderings and decreased slightly after this point. Tencel had the minimum thermal resistance values under all the circumstances, compared to the other fabrics. It increased slightly up to 8 launderings and decreased from this point to its initial value after 15 launderings. Considering the thickness variation presented in Table 2 and Figure 1 and the air permeability variation shown in Figure 2, increasing the laundering cycle number generally increased the thickness and decreased the air permeability up to a certain cycle number, however further increasing the number of laundering cycles yielded the reverse behaviour of these parameters. A proportional trend may be seen for the thermal resistance of the fabrics, namely, that increasing the number of laundering cycles increased the thickness and decreased the air permeability of fabrics up to a certain value and further increasing the number of launderings decreased the thickness and increased the air permeability, which slightly decreased the thermal resistance of the fabrics, in general. Although there is not a specific study investigating the thermal behaviour of natural and man-made cellulosic fibres upon repeated laundering, in the literature, according to the study of S. Kim et al ${ }^{17}$ the thermal insulation properties of polyester filled sportswear fabrics increased by increasing the number of laundering cycles up to 5 cycles and decreased smoothly after this point to 10 cycles. According to Nayak et al., the thermal resistance of aramid fabrics increases by increasing the number of laundering cycles. ${ }^{19}$ In addition, the changes in the thermal conductivity of laminated nanofiber webs with repeated laundering ${ }^{20}$ are similar to the results of the present study.

\section{CONCLUSION}

The effect of repeated laundering on the thermal comfort properties (thickness, air permeability, relative water vapour permeability and thermal resistance) of novel and conventional cellulosic fabrics, such as cotton, viscose, Viloft, Modal, Promodal and Tencel, was investigated in this study. ANOVA was conducted and the contributions of the factors, such as material type and repeated laundering, to the thermal comfort properties of the fabrics are shown as percentage. In addition, the regression curves were plotted and the variation of the related response with the number of laundering cycles, according to the material types, was shown. As a result of the experimental and statistical research, the belowmentioned conclusions can be drawn.

Thickness increases rapidly up to 5 launderings for all the material types, which can be related to the fact that fibres tend to protrude from the fabrics because of the mechanical effect of laundering and detergent on the fabrics. Further increasing the number of laundering cycles does not show a significant change on the fabrics, except in the case of Modal. The thickness variation is the highest for cotton, whereas it is minimum for Modal. This situation can be related to the high wet modulus of Modal fibres, which holds the fibres in the fabric structure.

Material type is more influential than repeated laundering on the air permeability of fabrics. Increasing the number of laundering cycles increases the thickness, which results in a decrease in air permeability. This case is more drastic for Tencel, because of its fibrillation property that causes an increase in the specific surface area of the fabrics.

Relative water vapour permeability is affected primarily by repeated laundering. It decreases after 10 launderings and increases from this point to 15 launderings for all the types of fabrics. The minimum RWVP is achieved by Viloft, since its crenulated surface resists water permeability. However, the maximum permeability is achieved by Modal and Promodal fabrics.

Thickness is known as the most influential parameter affecting thermal resistance values. However, in this study, the material type was found to be more influential than repeated laundering on the thermal resistance property of fabrics. Since the material type characteristics, such as the specific surface area, high wet strength and fibrillation properties, are different from fabric to fabric, these parameters are more influential than thickness. In general, thermal resistance increases with increasing the number of laundering cycles, which can be related to the thickness increase in fabrics. The maximum thermal resistance is achieved for cotton and Viloft.

In conclusion, both material type and repeated laundering are significant factors affecting the thermal comfort properties of fabrics. Polynosic fibres, such as Modal, Promodal and Tencel, showed high RWVP, relatively high air permeability and low thermal resistance, compared to other fabrics. However, cotton and 
Viloft demonstrated low air permeability, RWVP and high thermal resistance.

ACKNOWLEDGEMENT: Authors are thankful to the Research Fund of Erciyes University (project number FYL-2018-8230).

\section{REFERENCES}

1 E. P. A. Kumbasar, A. Marmarali and N. Oglakcioglu, AATCC Rev., 11, 46 (2011), WOS: 000295445000006, https://www.aatcc.org/pub/aatccreview/

2 O. Demiryurek and D. Uysalturk, Text. Res. J., 83, 1740 (2013), https://10.1177/0040517513478458

3 G. Soares, A. Magalhaes, A. Vasconcelos, E. Pinto and J. Santos, Cellulose Chem. Technol., 52, 113 (2018),

http://www.cellulosechemtechnol.ro/pdf/CCT12(2018)/p.113-121.pdf

4 A. Majumdar, S. Mukhopadhyay and R. Yadav, Int. J. Therm. Sci., 49, 2042 (2010), https://10.1016/j.ijthermalsci.2010.05.017

K. C. Schuster, F. Suchomel, J. Manner, M. AbuRous and H. Firgo, Macromol. Symp., 244, 149 (2006), https://onlinelibrary.wiley.com/doi/pdf/10.1002/masy. 200790001

6 M. Tausif, F. Ahmad, U. Hussain, A. Basit and T. Hussain, J. Clean. Prod., 89, 110 (2015), https://10.1016/j.jclepro.2014.11.011

7 S. K. An, H. J. Gam and H. T. Cao, Cloth. Text. Res. J., 31, 157 (2013), https://10.1177/0887302X13490069

8 A. Majumdar, J. Text. Inst., 102, 752 (2011), https://10.1080/00405000.2010.516929
9 C. MacKay, S. C. Anand and D. P. Bishop, Text. Res. J., 66, $151 \quad$ (1996), https://10.1177/004051759606600304

10 L. Quaynor, M. Nakajima and M. Takahashi, Text. Res. J., 69, $285 \quad$ (1999), https://10.1177/004051759906900408

11 L. Higgins, S. C. Anand, D. A. Holmes, M. E. Hall and K. Underly, Text. Res. J., 73, 357 (2003), https://10.1177/004051750307300414

12 L. Higgins, S. C. Anand, D. A. Holmes, M. E. Hall and K. Underly, Text. Res. J., 73, 407 (2003), https://10.1177/004051750307300507

13 L. Lau, J. T. Fan, T. Siu and L. Y. C. Siu, Text. $\begin{array}{llll}\text { Res. } & \text { J., } & \mathbf{7 2}, & 931\end{array}$ https://10.1177/004051750207201012

14 A. Fox and M. A. Moore, J. Test. Eval., 34, 181 (2006), https://10.1520/JTE14087

15 S. C. Duru and C. Candan, Text. Res. J., 83, 591 (2013), https://10.1177/0040517512456754

16 V. Midha, S. S. Kumar and M. N. Kumar, J. Text. Inst., $\quad \mathbf{1 0 8 ,} \quad 71 \quad$ (2017), https://10.1080/00405000.2016.1153873

17 F. A. P. Scacchetti and G. M. B. Soares, Cellulose Chem. Technol., 53, $363 \quad$ (2019), http://www.cellulosechemtechnol.ro/pdf/CCT34(2019)/p.363-371.pdf

18 S. Kim, E. Kim and Y. Park, Int. J. Cloth. Sci. Technol., 30, 428 (2018), https://10.1108/IJCST-092017-0149

19 R. Nayak, S. Kanesalingam, S. Houshyar, A. Vijayan, L. Wang et al., Fiber. Polym., 17, 954 (2016), https://10.1007/s12221-016-5863-7

20 L. Sumin, D. Kimura, K. H. Lee, J. C. Park and I. S. Kim, Text. Res. J., 80, 99 (2010), https://10.1177/0040517508102308 